\title{
Health status and health-related quality of life of municipal waste collection workers - a cross-sectional survey
}

\author{
Marcial Velasco Garrido*, Cordula Bittner, Volker Harth and Alexandra Marita Preisser
}

\begin{abstract}
Background: Waste collection workers are exposed to several occupational stressors which may affect their quality of life. Our aim was to assess the health status and health-related quality of life (HRQOL) of municipal waste collection workers of a big German city.

Methods: Cross-sectional study with a non-random sample of 65 (62 male, 3 female) workers of the Hamburg sanitation department, volunteering to participate in the study. We assessed the prevalence of reported health complaints and health problems. HRQoL was assessed with the self-administered EQ-5D-5L questionnaire and its visual analogue scale (VAS).

Results: The most common health problems were musculoskeletal complaints (back pain reported by $67.2 \%$, other musculoskeletal complaints $15.4 \%$ ). Asthma or chronic obstructive pulmonary disease (COPD) was reported by $15.4 \%$ of the workers. All participants reporting having a diagnosis of asthma or COPD had been or were active smokers. Our findings indicate an impaired HRQoL among the investigated occupational group. Regarding EQ-5D $68.3 \%$ reported at least "slight" problems in one or more dimensions, and almost one third (31.7\%) reported "no problems" in any dimension. Problems were most frequently reported in the dimension "pain/ discomfort" (64.1\% of the workers). The mean VAS value was 80.9 (13.2). The presence of back pain was associated with limitations in HRQoL (RR 3.1; $95 \%$-Cl 1.5-6.1). The EQ5D VAS score was statistically significantly lower among waste collectors with back pain (77.9 SD 14.1) compared to those with no back complaints (88.0 SD 7.6, $p<0.01$ ).

Conclusions: Back complaints are common among municipal waste collectors and are associated with considerable impairments in their HRQoL. Interventions to enhance ergonomic work are needed in order to reduce back complaints and enhance $H R Q O L$ in this occupational group.
\end{abstract}

Keywords: Refuse collection, Waste collection, Back complaints, HRQoL, EQ-5D-5L, Cross-sectional study

\section{Introduction}

Municipal solid waste generation varies across countries in relation to income level and rate of urbanization, with the OECD countries accounting for $44 \%$ of the 1.3 billion tonnes of waste generated yearly worldwide [1]. The duties of waste collectors usually include picking-up waste from its point of production, emptying refuse containers onto trucks, and delivering the waste to disposal and processing facilities. Despite the variety of collection

\footnotetext{
* Correspondence: m.velasco-garrido@uke.de

Institute for Occupational Medicine and Maritime Medicine (ZfAM), University Medical Center Hamburg-Eppendorf, Seewartenstrasse 10, 20459 Hamburg,
} Germany acterized by frequent lifting, carrying, pushing, and pulling of heavy objects' [2]. Besides the recurrent heavy physical activity, waste collectors are also exposed to bacteria, endotoxins, mould, allergens, particulate matter, irritant inhalants, vehicle exhaust, atmospheric conditions, noise, and psychomental stress. These multiple work demands and hazards result in a higher incidence of health problems and injuries compared to other occupations [2-4]. As one would expect, there is growing evidence that the incidence of respiratory problems and musculoskeletal complaints is higher among waste collectors than in other occupations $[5,6]$. 
Health-related quality of life (HRQoL) is a wellestablished aspect of health and general well-being, which can be measured with a variety of validated instruments [7]. In recent years, the issue of quality of life is increasingly being considered in occupational health research, with assessments of the relationship between occupational diseases and quality of life $[8,9]$; and in relation to specific occupations [10-12].

The aim of our study was to assess (i) the prevalence of health problems and (ii) the HRQoL of waste collectors, and (iii) to investigate their associations.

\section{Methods}

\section{Study design and participants}

We conducted a descriptive cross-sectional study among workers of the Hamburg sanitation department. The study was part of a broader occupational and ergonomic field study which assessed the working conditions and job strain of municipal waste collectors with qualitative interviews, real-life observation and objective strain measurements (e.g. mobile spiroergometry) [13]. For the study, waste collectors were recruited by the human resources department of the municipal waste collection services of the City of Hamburg with the involvement of the safety engineer and collection tour planners. Participation in the field study was voluntary and rewarded with two days off. The sampling method was predefined by the ergonomic study and aimed at representing the broad spectrum of working conditions in the collection tours (i.e. areas with low and high population density, areas with frequent architectonic barriers, predominant type and size of container, etc.) and the two main work groups (street waste collectors and household waste collectors). The sample size was also determined by the ergonomic field study. The final study group consisted of 65 persons (62 male and 3 female) who were all active (i.e. not on sick leave) at the time of data collection (between January and August 2013). The majority of participants (71\%) were working in the household waste collection service.

\section{Measurements}

Participants were invited to our Outpatient Clinic for Occupational and Environmental Health for a health check including a general clinical examination, 12-channel resting-ECG, lung function testing (spirometry and body plethysmography), as well as spiroergometry as described elsewhere [14]. All participants signed a written informed consent document after the examining physician had explained the health check-up and the study. Before undergoing the clinical interview and clinical examinations, the participants were asked to answer a questionnaire regarding current and past health problems and to self-assess their HRQoL. The health problems questionnaire listed organ systems and asked (yes/no questions) whether the participant 'suffered or had suffered from any disease of that system, providing examples of the most common conditions for each system. It also included questions on smoking habits and medical treatments. The questionnaire was used to support the subsequent clinical interview.

HRQoL was self-assessed with the EQ-5D-5L instrument $[15,16]$ in its German version. The instrument consists of a descriptive system with five dimensions ('mobility,' 'self-care,' 'usual activities,' 'pain/discomfort,' 'anxiety/depression') and a visual analogue scale (VAS). In the descriptive system, the participant is asked to report his/ her health state for each dimension on the present day (i.e. the day of answering the questionnaire) by ticking the most appropriate answer among five levels ('no problems', 'slight problems', 'moderate problems', 'severe problems', and 'extreme problems'; the word 'problems' is replaced by "pain or discomfort' in the fourth dimension and by 'anxious or depressed' in the fifth dimension). For each dimension, the answers are coded with a 1-digit number from ' 1 ' ('no problems') to ' 5 ' ('extreme problems'). The digits of the 5 dimensions are combined into a 5-digit number which describes the overall health state of the respondent [17]. For example '11111' indicates no problems in any of the dimensions; '21131' would indicate slight problems in mobility, moderate pain and discomfort and no problems in the other dimensions. In the EQ VAS, the self-rated health is visualized on a $20 \mathrm{~cm}$ vertical, visual analogue scale with endpoints labelled 'the best health you can imagine' ('100') and 'the worst health you can imagine' $(' 0$ ') and to write the number marked in the scale on a box [17]. The time horizon for the VAS is also the present day.

The clinical interview was structured around the abovementioned health problems questionnaire and aimed at ensuring the collection of relevant data on health problems.

\section{Statistical analysis}

Descriptive statistics are presented as median (interquartile range, IQR) or mean (standard deviation, SD) for continuous variables, and as frequency and percentage for categorical variables. The associations between health problems commonly reported and HRQoL were analysed calculating relative risk (RR) with $2 \times 2$ contingency tables and Fisher's exact test. Mean differences across groups were tested with unpaired Student's t. For multivariate analysis, logistic regression was performed adjusting for age, BMI and current smoking status, since these have been associated before with impairments in quality of life among adults $[18,19]$. Two-tailed $P$ values were calculated. Statistical analyses were carried out using PASW Statistics Software 18.0 (SPSS Inc., Chicago, IL, USA, IQR and Epi Info ${ }^{\text {тм }}$ 7.1.3.3 (Centers for Disease Control and Prevention, Atlanta, GA, USA). 
The study was approved by the Ethics Committee of the Hamburg Medical Association (register no. PV4524).

\section{Results}

Table 1 reports the characteristics of the study participants in comparison with the source population. Despite slight differences, the self-selected non-random sample was similar to the source population regarding age, gender distribution and years on the job. Vocational training prior to employment in the municipal waste collection services had been done more frequently by study participants. In general, waste collectors represent an aged collective, with the median age at 47.5 (IQR 10.6) years and $66.1 \%$ of participants being above 45 years old.

Mean body mass index (BMI) was $28.3 \mathrm{~kg} / \mathrm{m}^{2}$ (SD 3.8). Overweight (BMI $\geq 25 \mathrm{~kg} / \mathrm{m}^{2}$ ) was highly prevalent among participants $(83.1 \%)$; obesity (BMI $\geq 30 \mathrm{~kg} / \mathrm{m}^{2}$ ) was present in $29.2 \%$ of the waste collectors. The prevalence of smoking among the participants was $35.4 \%$; only $22.4 \%$ reported to have never smoked.

Table 2 summarizes the results regarding health problems. A total of $89.2 \%$ of the participants reported having at least one health problem. Considering vision limitations as a health problem raised the prevalence of health problems to $93.8 \%$. About one third reported currently being under medical treatment $(29.2 \%)$ or on long-term drug treatment (33.8\%). Most of the drug therapies $(60 \%)$ targeted cardiovascular diseases and cardiovascular risk factors. $11 \%$ of the participants reported that they took antidepressant drugs.

The most common health problem was back pain, reported by $67.2 \%$ of the participants. In the clinical examination, spinal percussion and/or palpation were painful in $11.5 \%$ of the waste collectors and the fingerfloor distance was over $10 \mathrm{~cm}$ in $19.3 \%$ of the study group. Other musculoskeletal complaints were reported by $15.4 \%$.

According to the answers to the questionnaire, asthma and COPD had a prevalence of $7.7 \%$ each. All participants
Table 2 Reported diseases and health problems. [N=65, multiple answers possible]

\begin{tabular}{lll}
\hline & Number & Percent \\
\hline Back complaints & 43 & 67.2 \\
Vision problems or eye diseases & 38 & 58.5 \\
Long-term drug treatment & 22 & 33.8 \\
Allergies & 21 & 32.3 \\
Currently under medical treatment & 19 & 29.2 \\
Cardiovascular diseases & 15 & 23.1 \\
Respiratory diseases & 13 & 20.0 \\
Hearing problems or ear diseases & 12 & 18.5 \\
Gastrointestinal diseases & 11 & 16.9 \\
Other musculoskeletal complaints & 10 & 15.4 \\
Psychiatric problems & 10 & 15.4 \\
Dermatological problems & 10 & 15.4 \\
Vertigo, Syncope & 8 & 12.3 \\
Neurological diseases & 5 & 7.7 \\
Diabetes & 3 & 4.6 \\
\hline
\end{tabular}

reporting a diagnosis of asthma or COPD had been or were active smokers. Lung function tests yielded an obstructive pattern $\left(\mathrm{FEV}_{1} / \mathrm{FVC}<70 \%\right)$ in $21.5 \%$ of the participants. Among those reporting a diagnosis of respiratory disease, $38.4 \%$ showed an obstructive pattern ( 3 of them had reported a diagnosis of asthma and 2 of COPD).

All but one participant answered the EQ-5D questionnaire; one participant did not rate the "anxiety/depression" dimension. Almost one third (31.7\%) of the participant waste collectors rated their health status as 'without problems' in any 5 dimensions (i.e. 11111) (Table 3). The rest reported at least 'slight' problems in at least one dimension. The dimension for which problems were most frequently reported was 'pain/discomfort' with $46.9 \%$, and $17.2 \%$ reported 'slight' or 'moderate' problems respectively. Almost one third (28.1\%) reported 'slight' or

Table 1 Participant characteristics compared to source collective

\begin{tabular}{|c|c|c|c|c|c|c|c|c|}
\hline & \multicolumn{4}{|c|}{ Study participants } & \multicolumn{4}{|c|}{ Source collective } \\
\hline & \multicolumn{4}{|c|}{$(N=65)$} & \multicolumn{4}{|c|}{$(\mathrm{N}=1,544)$} \\
\hline & Mean & SD & Number & Percent & Mean & SD & Number & Percent \\
\hline Age (years) & 45.5 & 8.3 & & & 46.5 & 9.4 & & \\
\hline \multicolumn{9}{|l|}{ Gender } \\
\hline Female & & & 3 & 4.6 & & & 31 & 2.1 \\
\hline Male & & & 62 & 95.4 & & & 1513 & 97.9 \\
\hline \multicolumn{9}{|l|}{ Previous vocational training } \\
\hline Yes & & & 52 & 80 & & & 1109 & 71.8 \\
\hline No & & & 13 & 20 & & & 435 & 28.2 \\
\hline Years working for the municipal waste collection service & 20.4 & 9.1 & & & 18.6 & 9.9 & & \\
\hline
\end{tabular}


Table 3 Frequency of health status (i.e. response patterns to the five-dimension descriptive part of $\mathrm{EQ5D}$ ). [N=63, frequency shown for patterns reported by more than one participant]

\begin{tabular}{lll}
\hline EQ5D Health Status & Number & Percent \\
\hline 11111 & 20 & 31.7 \\
11121 & 14 & 22.2 \\
21121 & 6 & 9.5 \\
11122 & 4 & 6.3 \\
11112 & 3 & 4.8 \\
31231 & 3 & 4.8 \\
11222 & 2 & 3.2 \\
21122 & 2 & 3.2 \\
21131 & 2 & 3.2 \\
\hline
\end{tabular}

'moderate' problems in the dimension 'mobility'. The only dimension for which 'severe' problems were reported was 'anxiety/depression'. None of the participants reported any problems in the dimension 'self-care'.

The distribution of the VAS scores is shown in Fig. 1. All but 3 participants rated their HRQoL in the VAS. The mean EQ5D VAS score was 80.9 (SD 13.2); the lowest score was 50, the highest 100 .

We explored the association between reported health problems and HRQoL in contingency tables for the conditions reported by at least one fifth of the participants (Table 4). Reported back complaints were associated with lower quality of life in the five-dimensional part of the EQ5D. The majority $(87.8 \%)$ of waste collectors with back pain had an HRQoL other than 11111. All participants reporting problems in the dimension 'mobility' had also reported back pain. The majority (88.4 \%) of participants reporting back pain had also reported at least 'slight' problems in the dimension 'pain/discomfort'. Back complaints were also associated with lower VAS score. The VAS score among waste collectors without back pain was statistically significantly higher than the VAS score of participants with back pain (88.0 SD 7.6 vs. 77.9 SD 14.1, $\mathrm{p}=0.0051$ ). VAS score was also

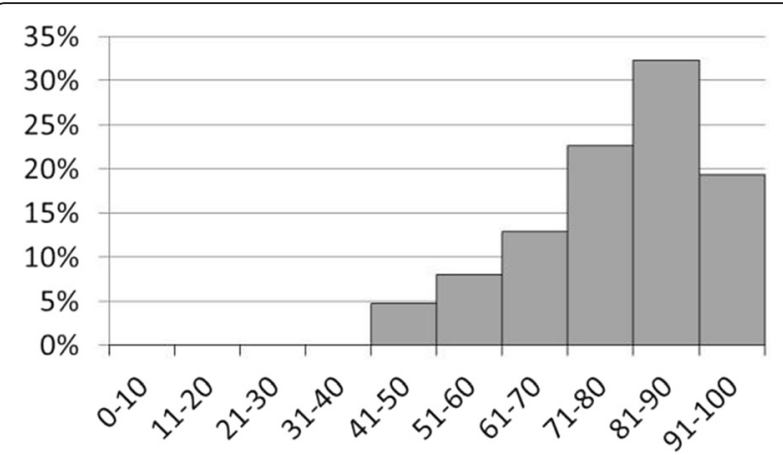

Fig. 1 Distribution of VAS-scores. [ $\mathrm{N}=62 ; 3$ missing values] statistically significantly lower among waste collectors under current medical treatment compared to those not in treatment (75.8 SD 14.8 vs. 85.0 SD 10.1, p =0.0001) and among waste collectors reporting allergies compared to those with no allergy (75.9 SD 15.1 vs. 83.3 SD 11.7, $\mathrm{p}=0.0408$ ). For all other conditions listed in Table 4 , there were no statistically significant differences in mean VAS score, although mean VAS score was always lower among waste collectors reporting the health problem or disease.

The association between back complaints and any limitation in quality of life (i.e. health status other than '11111') was still statistically significant after adjusting for age, BMI and current smoking status with logistic regression (OR 14.1; 95 \%-CI 3.4-59.0).

\section{Discussion}

This is the first study to examine health status and quality of life using a validated instrument, the EQ-5D, of waste collection workers, although sample size was small. Interestingly, we observed a high prevalence of back complaints which was strongly associated with limitations in health related quality of life in this occupational group.

Previous studies have reported a higher prevalence of respiratory problems, including workplace-related respiratory complaints, among waste collectors than in the general population $[3,5,6,20]$. This might be explained through the exposure against allergens and toxins contained in waste, seasonal allergens, and infectious agents [2]. Despite a higher prevalence of smokers and exsmokers as in the German general population [21], we unexpectedly found a similar prevalence of asthma and COPD among our sample of waste collection workers as reported by the German general population [22]. However, on the basis of lung function testing, we identified 9 subjects with obstructive ventilatory abnormalities who had not reported having a respiratory disease, indicating the possibility of a higher total prevalence of respiratory problems in our sample, as one would expect. A limitation of our study is that we did not ask about workplace-related respiratory complaints. This could explain the discrepancy between previous papers and ours regarding respiratory diseases.

In the present study we found a higher prevalence of back complaints among waste collectors compared to the German general population [23]. This result is in accordance with previous reports in the literature $[2,6]$. Although in our study we could not establish whether the reported back complaints were workplace-related, the available evidence indicates that waste collectors may have a higher incidence of musculoskeletal complaints than other occupations, equivalent to the findings of Kujier et al. [6]. In addition, musculoskeletal 
Table 4 Health problems and health-related quality of life limitations.

\begin{tabular}{|c|c|c|c|c|c|c|}
\hline \multirow[t]{2}{*}{ Health problem } & \multicolumn{2}{|c|}{$\begin{array}{l}\text { EQ5D } 11111 \text { (no } \\
\text { problems) }\end{array}$} & \multicolumn{2}{|c|}{$\begin{array}{l}\text { EQ5D other than } 11111 \text { (at least slight problems in at least one } \\
\text { dimension) }\end{array}$} & \multirow[t]{2}{*}{$\begin{array}{l}\text { RR } \\
\text { (raw) }\end{array}$} & \multirow[t]{2}{*}{$95 \% \mathrm{Cl}$} \\
\hline & Number & Percent & Number & Percent & & \\
\hline Back complaints & 5 & 25.0 & 36 & 85.7 & 3.07 & $1.54-6.10$ \\
\hline Vision problems or eye diseases & 11 & 55.0 & 26 & 60.5 & 1.01 & $0.76-1.52$ \\
\hline Long-term drug treatment & 6 & 30.0 & 16 & 37.2 & 1.11 & $0.79-1.55$ \\
\hline Allergies & 7 & 35.0 & 14 & 32.7 & 0.97 & $0.67-1.39$ \\
\hline Currently under medical treatment & 5 & 25.0 & 14 & 32.6 & 1.12 & $0.79-1.57$ \\
\hline Cardiovascular diseases & 3 & 15.0 & 12 & 27.9 & 1.24 & $0.89-1.72$ \\
\hline Respiratory diseases & 2 & 10.0 & 11 & 25.6 & 1.32 & $0.97-1.80$ \\
\hline RR: relative risk & & & & & & \\
\hline
\end{tabular}

disorders have been reported as accounting for about one fifth of sickness absence in the waste industry [24]. This is not surprising since handling waste containers represents a considerable strain for the musculoskeletal system, particularly of the back, through the combination of trunk lateral flexion, bending and torsion, as shown in ergonomic observations [25]. The waste collectors included in our study pick up two-wheeled waste containers (120 L volume) from houses and cellars (partially overcoming stairs) and also shift large four-wheeled waste containers $(240 \mathrm{~L})$ from storerooms to the truck. The ergonomic field study demonstrated through mobile spiroergometry (measurement of oxygen uptake) a high physical demand in the job of both refuse collectors and street cleaners [14]. The qualitative interviews also showed that the job is psychologically demanding because of time pressure, accident risks and perceived unfairness of quality control [26], which can also represent a strain related to musculoskeletal complaints. Further, we found a high prevalence of overweight in our sample. Overweight has been associated with back pain and other musculoskeletal complaints $[27,28]$ and may represent an additional strain for the musculoskeletal system.

Our findings indicate an impaired HRQoL among this occupational group as compared to the reference population: Whereas $47.5 \%$ of a representative sample of the German general population (i.e. including unemployed, chronically ill, etc.) reported the ideal EQ-5D health status [29], only one third (31.7\%) of the waste collectors rated their health status as without problems in all of the 5 dimensions. Taking the VAS score, HRQoL of waste collectors is comparable to that of German population samples. In a survey in the years $2002 / 2003$, VAS score among employees was 82.3 (SD not reported), whereas the general population had a mean VAS score of 77.4 (SD 19.0) [30]. A more recent survey (data from 2006-2008) reported a mean VAS score for the general German population of 79.8 (SD not reported) [31]. However, comparisons with published results for the general population are to be interpreted carefully since weighting for sociodemographic factors is not possible.

We found an association between back complaints and limitations in the quality of life of municipal waste collectors. After adjusting for BMI and smoking back pain remained the most important factor limiting HRQoL, although the precision of our estimate was limited by the small size of our study (95\% CI 3.4-59.0). Back pain has been described before as a limiting factor of HRQoL among industrial workers [32] and also among sedentary office workers [33]. Although our cross-sectional study design does not allow drawing conclusions on causality, the frequent limitations in the dimensions 'pain/discomfort' and 'mobility' of the EQ-5D point at back complaints as being one of the explaining factors for the limitation of overall HRQoL among the examined group of municipal waste collectors. This is also supported by the differences in VAS scores according to problems in the dimensions 'pain/discomfort' and 'mobility' of the EQ-5D. The mean VAS score among those without problems in the dimension 'pain/discomfort' indicated better health than among waste collectors with problems in this dimension (86.9 SD 7.4 vs. 77.3 SD 14.1, $\mathrm{p}=0.0077$ ). Similarly, the VAS score showed better results among those without problems in the dimension 'mobility' (83.2 SD 11.4 vs. 74.7 SD 14.8, p = 0.026). All in all our study shows an association between back complaints and limitations in HRQoL. Interventions addressing ergonomic handling of waste containers and street sweeping may reduce back complaints and finally contribute to improve quality of life among these workers.

To our knowledge, only few studies have been conducted on HRQoL among waste collectors and these were limited to the special group of gatherers of recyclable materials in Brazil. One study used the WHOQOL100 instrument but reported results too briefly to draw any sound conclusions [34], another one did not report having used a validated instrument to assess HRQoL and actually was focused on personal satisfaction [35], thus not being comparable with our work. 
To our knowledge ours is the first published systematic assessment of HRQoL among a group of municipal waste collectors using a validated instrument, the EQ-5D.

Besides the cross-sectional design, which lacks the temporary dimension for cause-effect relationships, another limitation of our study is the small self-selected non-random sample. Our group included workers from the household collection (including organic waste collection) and the street sweeping services. According to age, gender distribution and length of work in waste collection, the participants can be considered to be representative of the employees of the municipal waste collection services.

Recruitment of the participants by the human resources department could have introduced selection bias, i.e. through recruitment of healthier workers. Indeed all participants were active at the time of participating in the study - i. e. not on sick leave - thus a healthy worker effect could have led to underestimation of the prevalence of disease. Potential participants were approached in order to represent the broad spectrum of working conditions in the collection department and participated voluntarily. Since absolute confidentiality was warranted in our study and the health check and interview were conducted in our Institute, we do not think that reporting of symptoms and health problems has been relevantly affected by the recruitment method. Being afflicted with health problems could have been the motivation to participate in the volunteer study, which would bias our results. Since our study was only a part of a broader ergonomic study in which field observations had the prominent role, we do not think the main motive to participate was own health complaints. In the qualitative interviews of the broader ergonomic study, the reported main motivations to take part in the study were to show how hard the job of a waste collector is and to contribute to improvements in the company [26].

\section{Conclusions}

In summary, we found back complaints to be a frequent health problem among municipal waste collection workers, more frequent than in the general population. These complaints are associated with limitations in health-related quality of life and probably explain at least some of these impairments. Interventions to enhance ergonomic work processes in this occupational field are warranted in order to reduce musculoskeletal problems and should be evaluated taking HRQoL into account.

\footnotetext{
Abbreviations

BMI: Body mass index; Cl: Confidence interval; COPD: Chronic obstructive pulmonary disease; HRQOL: Health related quality of life; IQR: Interquartile range; OR: Odds ratio; RR: Relative risk; SD: Standard deviation; VAS: Visual analogue scale.
}

\section{Competing interests}

The authors declare that they have no competing interests.

\section{Authors' contributions}

MVG conceived and designed the study, acquired, analysed and interpreted the data and wrote the manuscript; CB acquired and interpreted the data and wrote the manuscript; $\mathrm{VH}$ interpreted data and revised the manuscript, AP conceived and designed the study, acquired and interpreted the data and wrote the manuscript. All authors read and approved the final manuscript.

\section{Acknowledgements}

We thank all participating waste collection workers of the Hamburg municipal waste collection services. We also thank Lutz Herrmann, safety engineer, for his support in participant recruitment. We are indebted to Thomas von Münster, MD, who conducted clinical interviews and examinations during the study. Finally we also thank Sabine Bößler and Anne Winkelmann for coordinating visits, performing medical technical procedures and for data managing.

The study was funded by a grant of 'Stadtreinigung Hamburg' (municipal sanitation department). The funder was neither involved in design, nor collection, nor analysis, nor interpretation of data, nor preparation of the manuscript. The funder was either involved in the decision to submit the manuscript.

Received: 10 February 2015 Accepted: 3 July 2015

Published online: 08 July 2015

\section{References}

1. Hoornweg D, Bhada-Tata P. What a waste: A global review of solid waste management. Urban Development Series, no 15. Washington DC: World Bank; 2012.

2. Kuijer PPFM, Frings-Dresen MH. World at work: Refuse collectors. Occup Environ Med. 2004;61:282-6.

3. Poulsen OM, Breum NO, Ebbehøj N, Hansen AM, Ivens UI, van Lelieveld D, et al. Collection of domestic waste. Review of occupational health problems and their possible causes. Sci Total Environ. 1995;170:1-19.

4. Ivens UI, Lassen JH, Kaltoft BS, Skov T. Injuries among domestic waste collectors. Am J Ind Med. 1998;33:182-9.

5. Athanasiou M, Makrynos G, Dounias G. Respiratory health of municipal solid waste workers. Occup Med (Lond). 2010;60:618-23.

6. Kuijer PPFM, Sluiter JK, Frings-Dresen MH. Health and safety in waste collection: Towards evidence-based worker health surveillance. Am J Ind Med. 2010;53:1040-64

7. Fitzpatrick R, Davey C, Buxton MJ, Jones DR. Evaluating patient-based outcome measures for use in clinical trials. Health Technol Assessment. 1998;2.

8. Karvala K, Uitti J, Luukkonen R, Nordman H. Quality of life of patients with asthma related to damp and moldy work environments. Scand J Work Environ Health. 2013;39:96-105

9. Knoeller GE, Mazurek JM, Moorman JE. Health related quality of life among adults with work-related asthma in the United States. Qual Life Res. 2013:22:771-80.

10. Chattopadhyay K, Chattopadhyay C, Kaltenhaler E. Health related quality-oflife of coal-based sponge iron plant workers in Barjora, India: a cross-sectional study. BMJ Open. 2014. doi:10.1136/bmjopen-2014-006047.

11. Rodríguez-Romero B, Pita-Fernández S, Pertega-Díaz S, Chouza-Insua M. Health-related quality of life in women working in the fishing industry measured through the Short-Form 36 questionnaire. Gac Sanit. 2013;27:418-24.

12. Jha A, Sadhukhan SK, Velusamy S, Banarjee G, Banarje A, Saha A, et al. Exploring the quality of life (QOL) in the Indian software industry: a public health viewpoint. Int J Public Health. 2012;57:371-81.

13. Zentralinstitut für Arbeitsmedizin und Maritime Medizin, Gesellschaft für Betriebsforschung und angewandte Arbeitswissenschaft, Institut für Arbeit und Technik e.V. Arbeitswissenschaftliche Untersuchung Entsorger Sytemmüllabfuhr/Straßenreinigung. Hamburg; 2014.

14. Preisser A, Zhou L, Velasco Garrido M, Harth V. Measured by the oxygen uptake in the field, the work of refuse collectors is particularly hard work: Are the limit values for physical endurance workload too low? Int Arch Occup Environ Health. 2015. [Epub ahead of print]

15. The EuroQol Group. EuroQol -a new facility for the measurement of healthrelated quality of life. Health Policy. 1990;16(3):199-208. 
16. Herdman M, Gudex C, Lloyd A, Janssen MF, Kind P, Parkin D, et al. Development and preliminary testing of the new five-level version of EQ-5D (EQ-5D-5L). Qual Life Res. 2011;20:1727-36.

17. van Reenen $M$, Janssen $B$. EQ-5D-5L User guide. Basic information on how to use the EQ-5D-5L instrument. Version 2.1, April 2015. http:// www.euroqol.org/fileadmin/user_upload/Documenten/PDF/Folders_Flyers/ EQ-5D-5L_UserGuide_2015.pdf. Accessed 06 July 2015.

18. Kearns B, Ara R, Young T, Relton C. Association between body mass index and health-related quality of life, and the impact of self-reported long-term conditions - cross-sectional study from the south Yorkshire cohort dataset. BMC Public Health. 2013. doi:10.1186/1471-2458-13-1009.

19. Rachiotis G, Behrakis PK, Vasiliou M, Yfantopoulos J. Quality of life and smoking among industrial workers in Greece. Med Lav. 2006;97:44-50.

20. Schantora AL, Casjens S, Deckert A, van kampen V, Neumann HD, Brüning T, et al. Prevalence of work-related rhino-conjunctivitis and respiratory symptoms among domestic waste collectors. Advs Exp Medicine Biology. 2014; doi: 10.1007/5584_2014_71.

21. Lampert T, von der Lippe $E$, Müters S. Prevalence of smoking in the adult population of Germany: results of the German Health Interview and Examination Survey for Adults (DEGS1). Bundesgesundheitsblatt Gesundheitsforschung Gesundheitsschutz. 2013;56:802-8.

22. Robert Koch Institut. Daten und Fakten: Ergebnisse der Studie "Gesundheit in Deutschland aktuell 2010". Beiträge zur Gesundheitsberichterstattung des Bundes. Berlin: Robert Koch Institut; 2010.

23. Neuhauser $\mathrm{H}$, Ellert $\mathrm{U}$, Ziese T. Chronic back pain in the general population in Germany 2002/2003: prevalence and highly affected population groups. Gesundheitswesen. 2005:67:685-93.

24. Holmes E. Review of sickness absence data in the waste and recycling industry. Health and Safety Executive Research Report RR750. London: Health and Safety Executive; 2009.

25. Backhaus C, Jubt KH, Post M, Ellegast R, Felten C, Hedtmann J. The musculoskeletal strain during pushing and pulling of waste containers. Z Arb Wiss. 2012;66:327-46

26. Martiny U, Frosch A, Paulus S. Sozialwissenschaftliche Untersuchung Subjektive Wahrnehmung und Einschätzung ihrer Arbeit durch die Entsorger. In: Zentralinstitut für Arbeitsmedizin und Maritime Medizin, Gesellschaft für Betriebsforschung und angewandte Arbeitswissenchaft, Institut für Arbeit und Technik e.V. (eds.). Arbeitswissenschaftliche Untersuchung Entsorger Sytemmüllabfuhr/ Straßenreinigung. Hamburg; 2014. p. 113-180.

27. Shiri R, Karppinen J, Leino-Arjas P, Slovieva S, Viikari-Juntura E. The association between obesity and low back pain: a meta-analysis. Am J Epidemiol. 2010;171:135-54. doi:10.1093/aje/kwp356.

28. Kortt M, Baldry J. The association between musculoskeletal disorders and obesity. Aust Health Rev. 2002;25:207-14.

29. Hinz A, Kohlmann T, Stöbek-Richter $Y$, Zenger M, Brähler E. The quality of life questionnaire EQ-5D-5L: psychometric properties and normative values for the general German population. Qual Life Res. 2014;23:443-7. doi:10.1007/s11136-013-0498-2.

30. König HH, Bernert S, Angermeyer MC. Health Status of the German population: results of a representative survey using the EuroQol questionnaire. Gesundheitswesen. 2005;67:173-82.

31. Mielck A, Reitmeier P, Vogelmann M, Leidl R. Impact of educational level on health-related quality of life (HRQOL): results from Germany based on the EuroQol 5D (EQ-5D). Eur J Public Health. 2013:23:45-9.

32. Morken T, Riise T, Moen B, Bergum O, Vigeland Hauge SH, Holien S, et al. Frequent musculoskeletal symptoms and reduced health-related quality of life among industrial workers. Occup Med. 2002;52:91-8.

33. del Pozo-Cruz B, Gusi N, Adsuar JC, del Pozo-Cruz J, Parraca JA, HernandezMocholí M. Musculoskeletal fitness and health-related quality of life characteristics among sedentary office workers affected by sub-acute, non-specific low back pain: a cross-sectional study. Physiotherapy. 2013;99:194-200.

34. de Barros Pimenta PA, dos Reis Santos SM, Pinto de Jesis MC, Martins Borges M, de Oliveira Marques GL, Francis Abdalla JG. The municipal solid waste and the quality of life of collectors of recyclable materials in Juiz de Fora, Minas Gerais. Work. 2012;41:5681-3.

35. Rabelo Almeida J, Tavares Elias E, Alves de Magalhaes M, Dias Vieira AJ. Age effect on the life quality and health of garbage collectors of an association in Governador Valadares, Minas Gerais State, Brazil. Cien Saud Col. 2009;14:2169-80.

\section{Submit your next manuscript to BioMed Central and take full advantage of:}

- Convenient online submission

- Thorough peer review

- No space constraints or color figure charges

- Immediate publication on acceptance

- Inclusion in PubMed, CAS, Scopus and Google Scholar

- Research which is freely available for redistribution 